\title{
Collision-Induced Dissociation of Uracil and Its Derivatives
}

\author{
Chad C. Nelson and James A. McCloskey \\ Departments of Medicinal Chemistry and Biochemistry, University of Utah, Salt Lake City, Utah, USA
}

\begin{abstract}
The collision-induced dissociation of protonated uracil has been studied by tandem mass spectrometry using models extensively labeled with stable isotopes, and derivatives of the kinds found in nucleic acids. Following collisional activation at $30 \mathrm{eV}$ translational energy, protonated uracil dissociates through two principal pathways which do not occur in electron ionization mass spectra: (1) elimination of $\mathrm{NH}_{3}$, almost entirely from $\mathrm{N}-3$, followed by loss of $\mathrm{CO}$ from $\mathrm{C}-4, \mathrm{O}^{4} ;(2)$ loss of $\mathrm{H}_{2} \mathrm{O}$, equally from $\mathrm{O}^{2}$ and $\mathrm{O}^{4}$. Elimination of $\mathrm{HNCO}$, also the principal dissociation process from odd-electron molecular ions, proceeds primarily by loss of $\mathrm{N}-3, \mathrm{C}-2, \mathrm{O}^{2}$, and $10 \%$ from $\mathrm{N}-1, \mathrm{C}-2, \mathrm{O}^{2}$. Several secondary dissociation products are formed with quantitative site specificity of skeletal atoms: $\mathrm{C}_{3} \mathrm{HO}^{+}(4-\mathrm{CO}, \mathrm{C}-5, \mathrm{C}-6) ; \mathrm{H}_{2} \mathrm{CN}^{+}$ $(\mathrm{N}-1, \mathrm{C}-6) ; \mathrm{C}_{2} \mathrm{NH}_{2}^{+}(\mathrm{N}-1, \mathrm{C}-5, \mathrm{C}-6)$. First-step dissociation reactions are interpreted in terms of pyrimidine ring opening at likely sites of protonation after collisional activation of $\mathrm{MH}^{+}$. Collision-induced dissociation mass spectra of uracils with structural themes common to nucleic acids (methylation, replacement of $\mathrm{O}$ by S, C-5 substitution) follow analogous reaction paths which permit assignment of sites of substitution, and exhibit ion abundance changes attributed to differences in substituent basicity and electron density. (I Am Soc Mass Spectrom 1994, 5, 339-349)
\end{abstract}

T The ionic dissociation reactions of heterocyclic compounds [1] have long been regarded as some of the most complex processes in mass spectrometry. Although not always correct, this view is due in large part to the difficulty in predicting a priori the reaction pathways of many heterocycles, coupled with the practical limitations of introduction of stable isotopes used to establish assignments, and the complexity of mass spectra that often result. As an experimental approach, tandem mass spectrometry [2] with collisional activation of the ions of interest is advantageous for such studies for several reasons: precursor-product ion relationships are more clearly defined than in the case of a single-dimension mass spectrum, and the origins and significance of low mass-to-charge ratio fragment ions are subject to much clearer interpretation; collisional activation effectively provides a means of introducing sufficient internal cnergy to promote extensive fragmentation [3] with the possibility that reaction channels that are absent or minimal in spontaneous dissociation spectra may be observed; and, when stable isotopes are employed, the nature of the multianalyzer experiment $[4,5]$ in which the isotopic compositions of precursor ions are well defined permits a more quantitative assessment of isotopic distribution in fragment ions. Address reprint requests to James A. McCloskey, Department of
Medicinal Chemistry, Skaggs Hall, University of Utah, Salt Lake City, U'T 84112
The nucleic acid bases constitute an important target for studies of heterocycle dissociation, primarily because of the significance of structural problems in biology and chemistry which involve modification of nucleic acid constituents, and the attendant advantages of mass spectrometry (for reviews see $[6,7]$ ). The diversity of structural themes built around the four central heterocyclic moieties (uracil/thymine, cytosine, adenine, guanine) suggests that detailed understanding of the principal collision-induced dissociation (CID) pathways of the four bases will permit extension to analogous spectra of many substituted pyrimidines and purines, as was the case with earlier work using electron ionization [8], as well as to biological studies in which stable isotopes are employed. Of particular interest is the observation that CID mass spectra of protonated adenine $[9,10]$ and guanine $[11,12]$ exhibit major product ions not observed in the corresponding electron ionization (EI) mass spectra [13, 14]. The dissociation reactions of collisionally activated adenine, using models sclectively labeled with ${ }^{13} \mathrm{C},{ }^{2} \mathrm{H}_{\text {, }}$ and ${ }^{15} \mathrm{~N}$, were found to proceed by four major pathways [10], three of which are of minor occurrence in the corrcsponding EI mass spectrum. There have been a number of studies of the CID mass spectra of nucleosides [7] but they are of less relevance because most of the collision energy is directed into cleavage of the glycosidic bond with little dissociation of the base. The applications of tandem mass spectrometry to xenobiotically modified bases and nucleosides has been recently reviewed [15]. 
The present study was initiated to examine the dissociation reactions of protonated uracil following collisional activation, using models selectively labeled with ${ }^{2} \mathrm{H},{ }^{13} \mathrm{C},{ }^{15} \mathrm{~N}$, and ${ }^{18} \mathrm{O}$ (see Figure 1), as well as substituted uracils which emphasize structural features found in nucleic acids (methylation, thiation, C-5 substitution). The objectives are to establish the extent to which CID reactions differ from those of oddelectron $\left(\mathrm{M}^{+}\right)$molecular ions from spontaneous dissociation of uracil [16] and its derivatives [17], and to determine the site selectivity of fragmentation reactions for comparison with analogous studies on protonated adenine [10].

\section{Experimental}

\section{Materials}

The following standards were obtained from Sigma (St. Louis, MO): uracil, uridine, 3-methyluracil, 5methyluracil, 2-thiouracil, 4-thiouridine, 5-hydroxyuridine, 5-methoxyuridine, and 2-thio-5-methyl-<smiles>O=c1cc[nH]c(=O)[nH]1</smiles><smiles></smiles>

$X^{1}={ }^{18} 0, X^{2}=160$, $\left[0^{2}-180\right]$ uracil $X^{1}={ }^{16} 0, X^{2}=180$. $\left[0^{4}-{ }^{18}\right.$ o]uracil<smiles>[2H]c1[nH]c(=O)[nH]c(=O)c1[2H]</smiles>
$\left[5,6-{ }^{2} \mathrm{H}_{2}\right]$ uracil<smiles></smiles>
$x={ }^{18} 0$ $\left[4-{ }^{13} \mathrm{C} .0^{4}-18\right.$ o]uracil<smiles>O=C1NC=CNC(=O)N1</smiles>
$\left[4,5-{ }^{13} \mathrm{C}_{2}\right]$ uracil

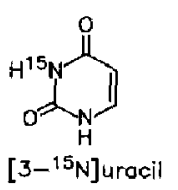
$\left[3-{ }^{15} \mathrm{~N}\right]$ uracil<smiles>Cc1c[nH]c(=S)[nH]c1=O</smiles>

2-thio-5-methyluracil

$$
\begin{aligned}
& \mathrm{R}^{1}=\mathrm{CH}_{3}, \mathrm{R}^{2}=\mathrm{H} \text {, } \\
& 3-\text { methyluracil } \\
& \mathrm{R}^{1}=\mathrm{H}, \mathrm{R}^{2}=\mathrm{CH}_{3} \text {. methyluracil }
\end{aligned}
$$

uridine. $\left[4-{ }^{13} \mathrm{C}\right]$ Uracil was obtained from Cambridge Isotope Labs (Woburn, MA). M. P. Schweizer provided $\left[4,5-{ }^{13} \mathrm{C}_{2}\right]$ uracil, 2-thiouridine, and 4-thiouracil. C. D. Poulter provided $\left[3-{ }^{15} \mathrm{~N}\right]$ uracil, the synthesis of which was previously reported [18]. $\left[\mathrm{O}^{2-}{ }^{18} \mathrm{O}\right]$ Uridine and $\left[5,6-{ }^{2} \mathrm{H}_{2}\right.$ ]uridine were synthesized in this laboratory by $\mathrm{K} . \mathrm{H}$. Schram in conjunction with earlier work [19, 20]. $\left[O^{4}-{ }^{18} \mathrm{O}\right]$ Uridine and $\left[4_{-}^{13} \mathrm{C}_{,} \mathrm{O}^{4}{ }^{18}\right.$ Oluracil were prepared from uridine and $\left[4-{ }^{13} \mathrm{C}\right]$ uracil, respectively, following the method of Puzo et al. [21]. Isotopic purity of all labeled compounds was approximately 99 atom $\%$ or greater.

\section{Mass Spectrometry}

CID mass spectra were acquired using a VG 70-SEQ instrument, consisting of a double-focusing magnetic sector mass analyzer (MS-1), rf-only quadrupole gas collision cell, and a quadrupole mass analyzer (MS-2), controlled by a VG-11/250J data system. All samples were dissolved in glycerol and ionized by fast atom bombardment $(\mathrm{FAB})$ by $\mathrm{Xe}$, using a saddle-field-type FAB gun (model FAB $11 \mathrm{~N}$, Ion Tech Ltd., Middlesex, U.K.) operated at $7.2-7.6 \mathrm{kV}$ and $1.1 \mathrm{~mA}$ discharge current. Precursor ions were mass-selected using MS-1 operated at 1000 resolution. High resolution mass spectra $(R=5000, M S-1)$ of uracil, 2-thiouracil, and 4-thiouracil were also obtained to eliminate glycerol matrix background interference ions. All CID spectra recorded from MS-2 were acquired at unit mass or greater resolution, and mass spectra were signalaveraged over five to ten scans.

CID mass spectra were produced using 25 or $30 \mathrm{eV}$ translational energy $\left(E_{\mathrm{LAB}}\right)$ of the incident precursor ion at a collision gas pressure corresponding to transmission of approximately $20 \%$ of the incident precursor beam, resulting in predominantly multicollision conditions. Krypton was used as the collision gas for all measurements because model studies of bases and nucleosides showed greater collision efficiency compared with Ar or Xe. Protonated bases were prepared either by $F A B$ ionization of the free base, or as fragment ions of the corresponding protonated nucleoside, for those cases in which the model compound was available as the nucleoside (as listed under Materials). For convenience, structures in Figure 1 and notations on mass spectra are represented in terms of the base. The conclusion $[7,10]$ that the nucleoside-derived fragment ion $\left(\mathrm{BH}_{2}^{+}\right)$is structurally identical to the $\mathrm{MH}^{+}$ ion from the corresponding base was validated by showing that the CID mass spectra of several model pairs (e.g., uridine and uracil, 2-thiouridine and 2thiouracil) were virtually indistinguishable (data not shown). These results are in accord with earlier measurements carried out using odd-electron base ions formed by electron ionization, which showed analogous equivalence between base fragments and molecular ions of the free bases $[22,23]$.
Figure 1. Structures and names of uracil derivatives studied, represented in each case as the corresponding neutral free base. 


\section{Isotopic Composition Calculations}

Isotopic and dissociation product compositions listed in Tables 1 and 2 were calculated as percentages of total ion current for each ion species. Therefore, $\%$ isotope retained $=100 a /(a+b)$, where $a-$ abundance of labeled ion and $b=$ abundance of unlabeled ion. The accuracy of percent composition values listed in the tables depends on relative ion abundances and signal-to-background ratios, but are generally considered to be within $\pm 5 \%$. Matrix background scans were obtained for every coincident precursor ion analyzed, and matrix ions have been assigned in the figures when possible. In cases where matrix and uracil product ions occur al the same nominal producl-ion mass, such as $m / z 97$ from CID of $m / z 115$ (e.g., glycerol $m / z 115-\mathrm{H}_{2} \mathrm{O}$ and $\mathrm{MH}^{+}$of $\left[\mathrm{O}^{2-18} \mathrm{O}\right]$ uracil - $\mathrm{H}_{2} \mathrm{O}$ ), contributions from the matrix have been estimated based on relative abundances of other matrix ions in the spectrum as compared with the matrix-only background scan. This type of background subtraction was considered to be consistent throughout the analyses of isotopically-labeled uracils; however, relative abundances of matrix background ions may vary to some extent as a function of matrix effects and surface phenomena [24]. High resolution (5000 in MS-1) or use of $\left[\mathrm{C}^{2} \mathrm{H}_{5}\right]$ glycerol matrix were utilized in some cases to eliminate background interferences.

\section{Results and Discussion}

\section{CID Mass Spectrum of Protonated Uracil}

The mass spectrum resulting from dissociation following collisional activation of protonated uracil is shown in Figure 2. Elemental compositions and structural origins were assigned to all ions in the spectrum based on corresponding mass shifts observed for uracil selectively-labeled with ${ }^{13} \mathrm{C},{ }^{15} \mathrm{~N}$, and ${ }^{2} \mathrm{H}$ (Figure 3 ), and on isotopic composition trends discussed below. Principal dissociation pathways, summarized in
Scheme I, were determined from collisional activation of the protonated base $\left(\mathrm{MH}^{+}\right)$and by mass-selection and activation of the first-step dissociation product ions $(m / 296,95,70)$ formed in the jon source of MS-1. These data show three main dissociation pathways from protonated uracil: (1) loss of $\mathrm{NH}_{3}(m / z$ 96) followed by elimination of a molecule of $\mathrm{CO}(\mathrm{m} / \mathrm{z} 68),(2)$ loss of $\mathrm{H}_{2} \mathrm{O}(\mathrm{m} / \mathrm{z} 95)$ followed by elimination of $\mathrm{CO}$ $(m / z 67)$ or HNCO $(m / z 52)$, and (3) expulsion of HNCO $(m / z \quad 70)$ with further losses of neutral molecules of $\mathrm{NH}_{3}, \mathrm{CO}, \mathrm{HCN}, \mathrm{C}_{2} \mathrm{H}_{2} \mathrm{O}$, and $\mathrm{C}_{2} \mathrm{HNO}$ to form secondary product ions of $m / z 53,42,43,28$, and 15 , respectively. Formation of $\mathrm{H}_{2} \mathrm{NCO}^{+}(\mathrm{m} / z$ 44) (corresponding to protonated $\mathrm{HNCO}$ ) is likely to be derived directly from $\mathrm{MH}^{+}$of uracil as a minor dissociation product in which the proton is retained on HNCO. The reported high energy CID mass spectrum derived from protonated uracil negative ion $(m / z 111)$ is much simpler and distinctly different, consisting of $m / 267$ (loss of $44 \mathrm{u}$ ) and $m / z 42\left(\mathrm{NCO}^{-}\right)$[11].

By comparison with protonated uracil, the EI mass spectrum of uracil [16] shows loss of HNCO as the only major decomposition process directly derived from the odd-electron molecular ion. This elimination primarily involves loss of $\mathrm{C}-2$ and $\mathrm{N}-3$ through a retro-Diels-Alder mechanism, as established by Rice et al. [16], and has also been observed as a major reaction pathway of substituted uracils and other pyrimidines 「17l. Although the odd-electron species undergoes relatively few further decompositions following loss of $\mathrm{HNCO}$ by spontaneous dissociation, elimination of $\mathrm{CO}$, $\mathrm{HCN}$, and $\mathrm{C}_{2} \mathrm{HO}$ closely parallel some pathways identified in the present study following the dissociation of HNCO from protonated uracil. Principal decomposition routes involving loss of $\mathrm{NH}_{3}$ and $\mathrm{H}_{2} \mathrm{O}$ occurring from $\mathrm{MH}^{+}$of uracil (Scheme I) probably result from the availability of an additional hydrogen and protonation-site directed dissociation mechanisms, discussed further below.

Table 1 lists isotopic-labeling distributions, compositions, and site selectivity of the principal dissociation

Table 1. Principal dissocialion products of protonated uracil

\begin{tabular}{|c|c|c|c|c|}
\hline Product Ion & $\begin{array}{c}\text { Mass-to-Charge } \\
\text { Ratio }\end{array}$ & Atom(s) Lost & $\%^{a}$ & Figure 3 \\
\hline$\overline{\left[\mathrm{MH}^{+}-\mathrm{NH}_{3}\right]}$ & 96 & $\begin{array}{l}\mathrm{N}-1 \\
\mathrm{~N}-3\end{array}$ & $\begin{array}{r}7 \\
93\end{array}$ & $f$ \\
\hline$\left[\mathrm{MH}^{+}-\mathrm{H}_{2} \mathrm{O}\right]$ & 95 & $\begin{array}{l}O^{2} \\
O^{4}\end{array}$ & $\begin{array}{l}50 \\
50\end{array}$ & $\begin{array}{l}a, b, e \\
a, b, e\end{array}$ \\
\hline$\left[\mathrm{MH}^{+}-\mathrm{HNCO}\right]$ & 70 & $\begin{array}{l}\mathrm{N}-1, \mathrm{C}-2, \mathrm{O}^{2} \\
\mathrm{~N}-3, \mathrm{C}-2, \mathrm{O}^{2} \\
\mathrm{~N}-3, \mathrm{C}-4, \mathrm{O}^{4}\end{array}$ & $\begin{array}{r}10 \\
87 \\
3\end{array}$ & $\begin{array}{l}a \\
a, f \\
e, f\end{array}$ \\
\hline$\left[\mathrm{MH}^{+}-\mathrm{NH}_{3}-\mathrm{CO}\right]$ & 68 & $\begin{array}{l}\mathrm{N}-3, \mathrm{C}-4, \mathrm{O}^{4} \\
\mathrm{~N}-3, \mathrm{C}-2, \mathrm{O}^{2}\end{array}$ & $\begin{array}{l}90 \\
10\end{array}$ & $\begin{array}{l}b, c, d, e \\
b, c, d, e\end{array}$ \\
\hline$\left[\mathrm{MH}^{+}-\mathrm{H}_{2} \mathrm{O}-\mathrm{CO}\right]$ & 67 & $c-2,0^{2}, o^{4}$ & 100 & $a, c, d$ \\
\hline
\end{tabular}

\footnotetext{
apercent distribution of products for each mass-to-charge ratio value is listed, following corrections for matrix background contributions. For low-intensity product ions, the percentage value listed is subject to about $\pm 5 \%$ error.
} 
Table 2. Minor dissociation products of protonated uracil

\begin{tabular}{|c|c|c|c|c|}
\hline Product lon & $\begin{array}{c}\text { Mass-to-Charge } \\
\text { Ratio }\end{array}$ & Atom(s) Retained & $\%^{a}$ & Figure 3 \\
\hline$\left[\mathrm{MH}^{+}-\mathrm{HNCO}-\mathrm{NH}_{3}\right]$ & 53 & $\overline{\mathrm{C}-4}, \overline{\mathrm{O}^{4}}, \overline{\mathrm{C}-5}, \overline{\mathrm{C}-6}$ & 100 & $\overline{b, c}, \bar{d}, \mathrm{e}$ \\
\hline$\left[\mathrm{MH}^{+}-\mathrm{H}_{2} \mathrm{O}-\mathrm{HNCO}\right]$ & 52 & $N-3, C-4, C-5, C-6$ & 100 & $c, d, e, f, g$ \\
\hline $\mathrm{IMH}^{+}-\mathrm{C}_{3} \mathrm{H}_{3} \mathrm{NO}$ & 44 & $\begin{array}{l}N-3, C-2, O^{2} \\
N-3, C-4, O^{4}\end{array}$ & $\begin{array}{l}50 \\
50\end{array}$ & $\begin{array}{l}a, e, f \\
a, c, e, f\end{array}$ \\
\hline$\left[\mathrm{MH}^{+}-\mathrm{HNCO}-\mathrm{HCN}\right]$ & 43 & $C-4, O^{4}, C-5$ & 100 & $b, c, d, e$ \\
\hline$\left[\mathrm{MH}^{+}-\mathrm{HNCO}-\mathrm{CO}\right]$ & 42 & N-1, C-5, C-6 & 100 & $d_{r} \mathbf{g}$ \\
\hline$\left[\mathrm{MH}^{+}-\mathrm{H}_{2} \mathrm{O}-\mathrm{CO}-\mathrm{HCN}\right]$ & 40 & $N-1, C-5, C-6$ & 100 & d. $\mathbf{g}$ \\
\hline$\left[\mathrm{MH}^{+}-\mathrm{HNCO}-\mathrm{C}_{2} \mathrm{H}_{2} \mathrm{O}\right]$ & 28 & $N-1, C-6$ & 100 & $\mathrm{~g}$ \\
\hline$\left[\mathrm{MH}^{+}-\mathrm{HNCO}-\mathrm{C}_{2} \mathrm{HNO}\right.$ & 15 & $\begin{array}{l}C-5 \\
C-6\end{array}$ & $\begin{array}{l}55 \\
45\end{array}$ & $\begin{array}{l}\text { d. } \mathbf{g} \\
\text { d, } \mathbf{g}\end{array}$ \\
\hline
\end{tabular}

\footnotetext{
apercent distribution of products for each mass-to-charge ratio value is listed following corrections for natrix background contributions. For low-intensity product ions, the percentage value listed is subject to about $\pm 5 \%$ error
}

reactions and several minor product ions of protonated uracil, which were determined from the mass spectra of the isotopically-labeled uracils. Isotopic distributions in the CID mass spectra of all of the labeled uracils (Figure 3 ) and CID spectra resulting from collisional activation of the primary dissociation products were instrumental in determining reaction paths to several low-intensity ions, such as $m / z 15$ and $m / z 28$. These low mass ions are difficult to distinguish from background in conventional mass spectra, but can be unambiguously and reproducibly measured in the tandem analyzer experiment.

\section{Site of Protonation of Uracil}

In aqueous solution, the keto form of uracil is the preferred tautomer, and uracil is predominantly protonated at the $\mathrm{O}^{4}$ position $[25,26]$. Molecular orbital calculations also predict the keto tautomer to be the preferred neutral form in the gas phase [27, 28] (based in part on studies with thymine), and for protonation to occur at either $\mathrm{O}^{2}$ or $\mathrm{O}^{4}$, where the $\mathrm{O}^{4}$ position is the most stable site of protonation [28]. Significant

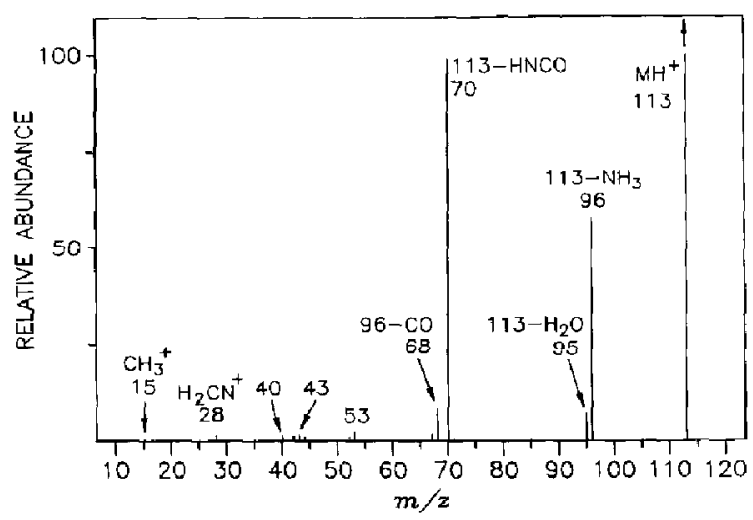

Figure 2. CID mass spectrum of protonated uracil. geometric and electronic structural changes accompany protonation. Following protonation, changes are found in bond lengths and angles near the protonation site and extensive charge delocalization of the keto tautomeric form occurs, resulting in several relatively stable aromatic tautomeric structures in the gas phase $[27,28]$. However, the stability of the resultant protonated tautomeric forms of thymine (or uracil) also indicate that either $\mathrm{O}^{2}$ or $\mathrm{O}^{4}$ is preferred (approximately equaliy) for protonation [27]. It is reasonable to assume, therefore, that different populations of protonated uracil (predominantly protonated at $\mathrm{O}^{2}$ or $\mathrm{O}^{4}$ ) coexist in the gas phase following ionization. Additionally, these principal mass-selected species, when subjected to collisional activation, are likely to undergo proton affinity changes concomitant with dissociation and proton or hydrogen migration and isomerization reactions probably occur as a result of collisional activation [29].

\section{Loss of $\mathrm{NH}_{3}$ and $\mathrm{H}_{2} \mathrm{O}$ from Protonated Uracil}

Protonated uracil eliminates a molecule of ammonia with a high degree of selectivity from the $\mathrm{N}-3$ position, as determined from the CID spectrum of $\left[3-{ }^{15} \mathrm{~N}\right]$ uracil (Figure 3f) and as indicated in Table 1. A second principal dissociation route originating from $\mathrm{MH}^{+}$of uracil involves loss of a molecule of $\mathrm{H}_{2} \mathrm{O}$ that occurs about equally from positions $\mathrm{O}^{2}$ and $\mathrm{O}^{4}$, based on the relative intensities observed for $m / z 95$ and 97 in the spectra of ${ }^{18} \mathrm{O}$-labeled uracils (Figure $3 a$ and $b$ ) and taking into account contributions from matrix background ions. The occurrence of these dissociation pathways, which are nonexistent in the EI mass spectrum of uracil [16], are interpreted in terms of initial ring opening at the N-3 position, as shown by eqs. 1 and 2 in Scheme II. Intermediate structures $a$ or $b$ are formed depending on whether the initial site of protonation is at $\mathrm{O}^{4}$ or $\mathrm{O}^{2}$. Although opportunities exist for hydrogen migration and isomerization reactions, Structures $a$ 

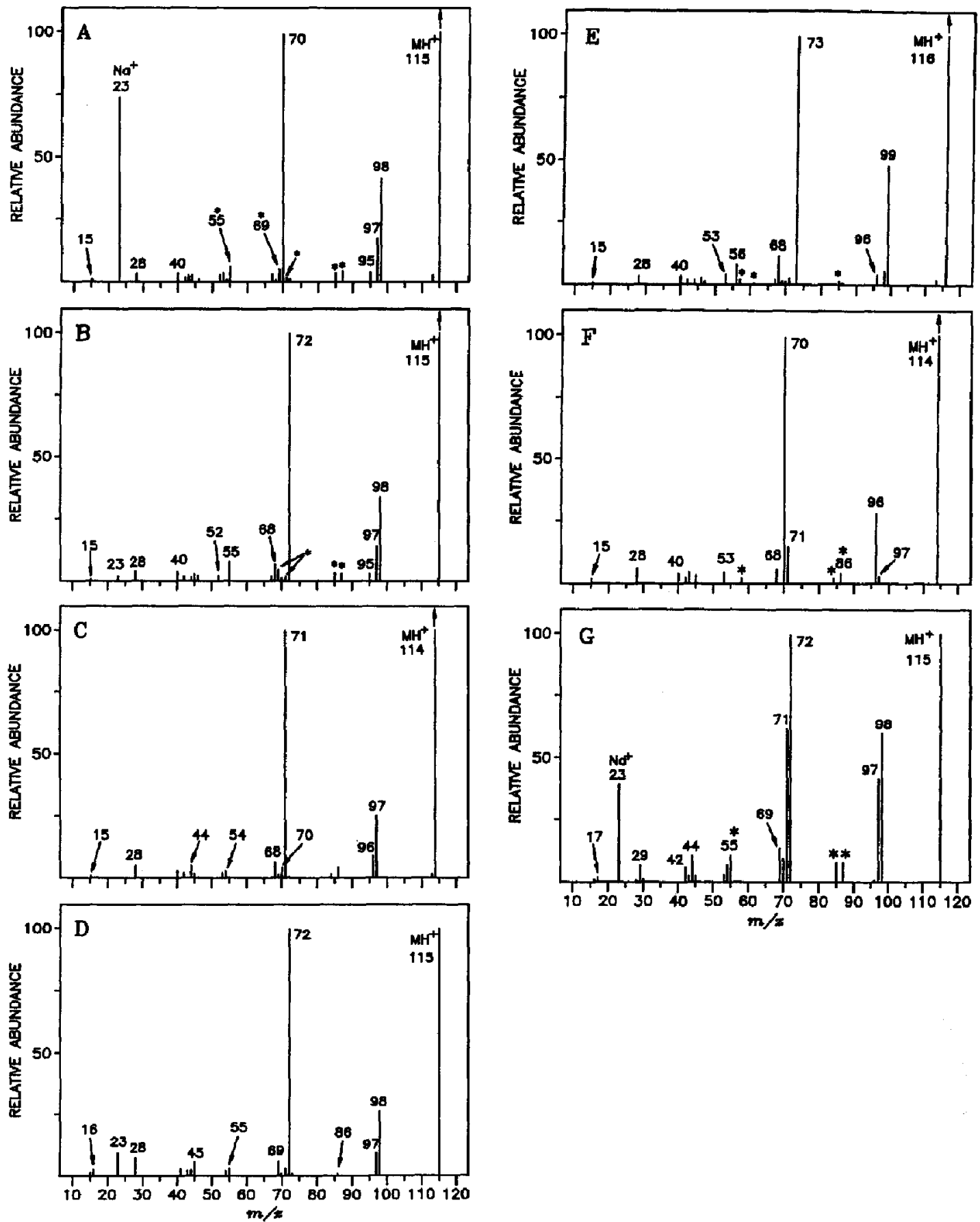

Figure 3. CID mass spectra of isotopically labeled protonated uracils. (a) $\left[\mathrm{O}^{2}{ }^{18} \mathrm{O}\right] \mathrm{Uracil}$; (b) $\left[\mathrm{O}^{4}{ }_{-18} \mathrm{O}\right]$ uracil; (c) $\left[4-{ }^{13} \mathrm{C}\right]$ uracil; (d) $\left[4,5-{ }^{13} \mathrm{C}_{2}\right]$ uracil; (e) $\left[4-{ }^{13} \mathrm{C}, \mathrm{O}^{4}-18\right.$ O]uracil; (f) $\left[3-{ }^{15} \mathrm{~N}\right]$ uracil; (g) $\left[5,6-{ }^{2} \mathrm{H}_{2}\right.$ luracil. $\mathrm{Na}^{+}(\mathrm{m} / z 23)$ in parels $(\mathrm{a}),(\mathrm{b}),(\mathrm{d})$, and $(\mathrm{g})$ results from mass coselection of the relatively abundant glycerol $+\mathrm{Na}^{+}$adduct ion of $\mathrm{m} / \mathrm{z}$ 115. Other ions due principally to background are denoted by asterisks. 


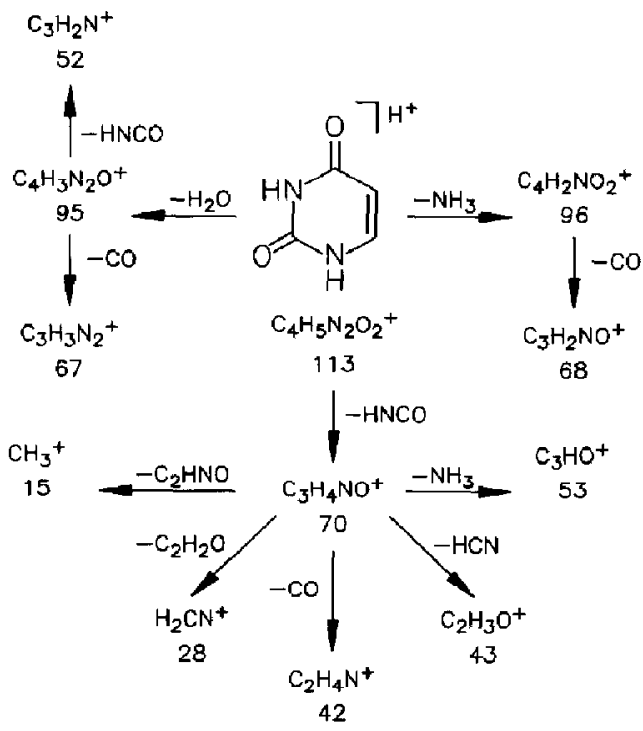

Scheme I. CID pathways of protonated uracil, determined from isotopic labeling patterns and by mass selection and activation of fragment ions, $m / z 70$ and 96 .<smiles>CNC(=O)NC1CCCCC1=O</smiles><smiles>O=C=NC=CC(O)=NC=[O+]</smiles><smiles>C#CC=C=NC=CC(N)=O</smiles>

a<smiles>O=c1cc[nH]c(=O)[nH]1</smiles><smiles>C#CCNC(O)=NC=C=O</smiles><smiles>NC(=O)N/C=C\C=[O+]</smiles>

(3)<smiles>O=C1NNc2c([nH]ccc2=O)N1</smiles><smiles></smiles>

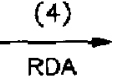

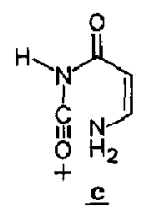

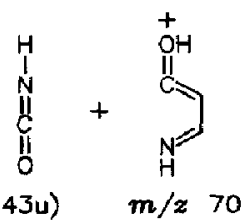

Scheme II. Initial reactions of protonated uracil following collisional activation. and $b$ can be reasonably represented by either of the tautomeric forms shown in equilibrium in Scheme II. These structures can be used to visualize further dissociation mechanisms for eliminations of $\mathrm{NH}_{3}$ and $\mathrm{H}_{2} \mathrm{O}$ and subsequent losses of $\mathrm{CO}$, shown in Scheme I. Elimination of $\mathrm{NH}_{3}(m / z$ 96) from $\mathrm{N}-3$ can readily occur from either intermediate $a$ or $b$ following hydrogen migration to the N-3 position. Alternatively, protonation at $\mathrm{N}-1$, which is predicted to be a less favorable site for initial protonation [28], yields intermediate $c$ with subsequent expulsion of $\mathrm{NH}_{3}$ from $\mathrm{N}-1$. Table 1 shows this process to be a minor dissociation pathway. The elimination of a significant proportion of $\mathbf{N H}_{2} \mathrm{D}$ $\left(m / z\right.$ 97), in addition to $\mathrm{NH}_{3}(m / z$ 98) from $[5,6-$ ${ }^{2} \mathrm{H}_{2}$ ]uracil (Figure $3 \mathrm{~g}$ ) demonstrates significant participation of carbon-bound hydrogen in the expulsion. (See additional comments in the following section dealing with loss of $\mathrm{HNCO}$.)

Equal loss of $\mathrm{H}_{2} \mathrm{O}$ from $\mathrm{MH}^{+}$of uracil from the $\mathrm{O}^{4}$ and $\mathrm{O}^{2}$ positions (see Table 1 and Figure $3 a$ and $b$ ) is consistent with initial protonation at both $\mathrm{O}^{4}$ and $\mathrm{O}^{2}$ sites. Subsequent dissociation from intermediates a and $b$, in which formation of imide moieties of $a(\mathrm{~N}-3$, $\mathrm{C}-4$, and $\left.\mathrm{O}^{4}\right)$ and $b\left(\mathrm{~N}-3, \mathrm{C}-2\right.$, and $\left.\mathrm{O}^{2}\right)$ lead to approximately equal participation through similar dissociation mechanisms for loss of $\mathrm{H}_{2} \mathrm{O}\left(\mathrm{m} / \mathrm{z}\right.$ 95). The ${ }^{18} \mathrm{O}$-labeled uracil CID mass spectra also demonstrate that loss of $17 \mathrm{u}$ from $\mathrm{MH}^{+}(\mathrm{m} / \mathrm{z}$ 96) from uracil cannot be accounted for by loss of the $\mathrm{OH}$ radical.

Positional selectivity is high for expulsion of a molecule of $\mathrm{CO}$ in both dissociation pathways subsequent to loss of ammonia or water (Scheme I). In the $\mathrm{NH}_{3}$ pathway, $\mathrm{CO}$ is primarily lost from $\mathrm{C}-4$ and $\mathrm{O}^{4}$, as shown by Figure $3 \mathrm{e}$, to generate $m / z$ 68 (Table 1 ). By contrast, the fragment ion at $m / z 68$ in the EI spectrum of uracil is comprised of $\mathrm{N}-1, \mathrm{C}-6, \mathrm{C}-5, \mathrm{C}-4$, and $\mathrm{O}^{4}$ and further dissociates by loss of a molecule of $\mathrm{CO}$ to form $m / z 40[8,16]$. This pathway is not observed from collisional activation of protonated uracil (Scheme I), as demonstrated by direct CID of $m / z 96$ as the incident ion (data not shown). In the $\mathrm{H}_{2} \mathrm{O}$-loss pathway, $\mathrm{CO}$ is selectively eliminated from $\mathrm{C}-2$ and $\mathrm{O}^{2}$ forming $m / z 67$ (Table 1), indicating that this decomposition occurs only as a consequence of initial $\mathbf{H}_{2} \mathrm{O}$ loss from the $\mathrm{O}^{4}$ position and originates only from intermediate $a$. This unique dissociation serves to illustrate the complexity of reaction pathways that exist even at the first-step dissociation level.

The low-intensity ion at $m / z 96$ in the CID spectrum of $\left[5,6-{ }^{2} \mathbf{H}_{2}\right]$ uracil (Figure $3 \mathrm{~g}$ ) shows that a small percentage of either $\mathrm{ND}_{2} \mathrm{H}$ or $\mathrm{HDO}$ loss occurs from protonated uracil, indicating that initial elimination of $\mathrm{H}_{2} \mathrm{O}$ primarily does not involve $\mathrm{H}-5$ or $\mathrm{H}-6$, and loss of $\mathrm{NH}_{3}$ involving both $\mathbf{H}-5$ and $\mathrm{H}-6\left(\mathrm{ND}_{2} \mathrm{H}\right)$ is quite limited. The small degree of $19 \mathrm{u}$ loss $\left(\mathrm{ND}_{2} \mathrm{H}\right.$ or $\left.\mathrm{HDO}\right)$ indicates that extensive hydrogen randomization involving H-5 and H-6 prior to these first-step dissociations reactions does not occur or is relatively insignificant. 


\section{Loss of HNCO}

The third major dissociation reaction arising from protonated uracil is loss of a molecule of $\mathrm{HNCO}$, which affords the most abundant product ion $(\mathrm{m} / z$ 70) resulting from collisional dissociation (Figure 2). In the EI spectrum, expulsion of HNCO by a retro DielsAlder (RDA) mechanism is the only major decomposition process occurring directly from the molecular ion, as determined from metastable ions [16]. This structurally characteristic reaction is important for identification of substitutions occurring at the $\mathrm{C}-2$ and N-3 positions of the pyrimidine structure [17]. In the case of negative ions, $\mathrm{HNCO}$ is expelled from the $\left[\mathrm{M}-\mathrm{H}^{-}\right.$ ion of the corresponding ribonucleoside (uridine) following collisional activation [30, 31], but apparently not from the deprotonated base [11]. (This latter point is not clear; the text of Ref. [11] states that the pyrimidine base $[\mathrm{M}-\mathrm{H}]^{-}$ions lose $43 \mathrm{u}$, but the tabulated spectrum lists loss of 44 u.) Following low-energy collisional activation, expulsion of $43 \mathrm{u}$ from $m / z 111$ is a trace process (P. F. Crain, unpublished experiment).

Isotopic labeling demonstrates that elimination of $\mathrm{HNCO}$ from $\mathrm{MH}^{+}$of uracil occurs through at least three separate mechanisms, as shown by sites of positional origins of atoms in Table 1. An RDA mechanism (requiring protonation at $\mathrm{O}^{4}$ or $\mathrm{N}-1$ ), shown by eq. 4 in Scheme II, can account for the majority of HNCO loss from the $\mathrm{C}-2$ and $\mathrm{N}-3$ positions, in accordance with earlier reported mechanisms with EI ionization [16]. Intermediate ions $b$ and $c$ in Scheme II may also readily dissociate by loss of $\mathrm{HNCO}$ from the $\mathrm{C}-2$ and $\mathrm{N}-3$ positions. It is reasonable to assume that a combination of these reaction mechanisms results in positional selectivity for loss of HNCO from C-2 and N-3. Table 1 also shows that minor reaction paths exist for site-selective loss of HNCO from N-1, C-2 and N-3, $\mathrm{C}-4$, both of which occur through decomposition of intermediate $a$. Corresponding mass shifts following collisional activation of all of the selectively-labeled uracils (Figure 3) support these site-specific eliminations. For example, the $\left[3-{ }^{15} \mathrm{~N}\right]$ uracil spectrum, in Figure $3 \mathrm{f}$ shows a $10 \%$ loss of $\mathrm{HNCO}$ from $\mathrm{N}-1$ and $\mathrm{C}-2$ $(m / z 71)$ and a $90 \%$ loss of HNCO involving N-3, C-2, and $\mathrm{C}-4(\mathrm{~m} / z \mathrm{z})$.

Evidence for extensive hydrogen-transfer processes or rearrangement reactions involved in the principal dissociation pathway for loss of HNCO are observed in the CID spectrum of $\left[5,6-{ }^{2} \mathrm{H}_{2}\right]$ uracil (Figure $3 \mathrm{~g}$ ). For instance, the active hydrogens (principally at $\mathrm{N}-3$ ) of uracil are not exclusively lost as part of the HNCO elimination, as would be predicted from an RDA mechanism or from simple cleavage of the intermediate structures in Scheme II. It was previously suggested by deuterium labeling experiments in the EI mass spectra of uracil that the active hydrogen at $\mathrm{N}-3$ is lost as part of the RDA reaction [16]. In the case of collisional activation of protonated uracil, the relatively-intense peak at $m / z 71\left(\left[5,6-{ }^{2} \mathrm{H}_{2}\right]\right.$ uracil, Fig- ure 3g) corresponds to loss of DNCO from the molecular ion. This elimination requires hydrogen-rearrangement processes involving either $\mathrm{D}-5$ or $\mathrm{D}-6$ prior to or concomitant with elimination of $\mathrm{HNCO}$. Mechanisms for hydrogen transfer to the $\mathrm{O}^{4}$ position, for example, have been previously proposed in EI spectra of uracil [16], and $\mathrm{H}$-migrations have been observed under a variety of experimental conditions in conjunction with RDA-type reactions [30-34]. The similarity of isotopic patterns in Figure $3 \mathrm{~g}$ for $m / z$ 71-72 [MH $\left.{ }^{+}-\mathrm{HNCO}\right]$ compared with $m / z$ 97-98 $\left[\mathrm{MH}^{+}-\mathrm{NH}_{3}\right]$ suggests the possibility of selective hydrogen interchange between $\mathrm{D}-5$ or D-6, and $\mathrm{H}-3$ or the proton of ionization, in the molecular ion prior to dissociation. The mechanism of hydrogen migration in the present case has not been further pursued, although it is noted that migration of carbon-bound deuterium in the CID of protonated adenine has also been observed [10].

\section{Compositions of Minor Product Ions}

The CID mass spectrum of uracil contains several relatively low-abundance product ions which dissociate with an unexpectedly high level of site specificity, as summarized in Table 2 . These low-mass ions are derived from the secondary dissociation pathways shown in Scheme $\mathbf{I}$ and were determined by direct collisional activation of the product ions resulting from the principal dissociation pathways, $m / z 96$ and 70 , by mass selection and activation of each of these ion species generated in the ion source. The CID mass spectrum of $m / z 70$ ion obtained in this fashion is shown in Figure 4.

The mass spectrum from $m / z 70$ reveals pathways to five different product ions (Scheme I) and demonstrates that dissociation paths leading to certain product ions (i.e., $m / z 52$ and 40 ) are not derived via the $\left[\mathrm{MH}^{+}-\mathrm{HNCO}(m / z 70)\right.$ primary pathway. The product ion at $m / z 52$ is highly site-specific for the $\mathrm{N}-3$

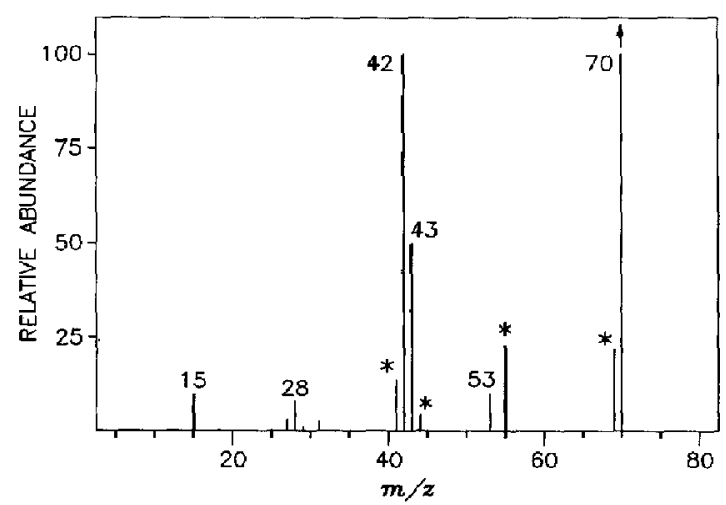

Figure 4. Mass spectrum resulting from CID of $m / z$ 70 fragment ion formed in the ion source of MS-1 from protonated uracil. Ions due principally to background are denoted by asterisks. 
through C-6 atoms of the pyrimidine ring (Table 2) and must occur via intermediate $a$ by subsequent losses of $\mathrm{H}_{2} \mathrm{O}$ (specifically from $\mathrm{O}^{4}$ ), then $\mathrm{HNCO}$ (selectively lost from $\mathrm{N}-1, \mathrm{C}-2, \mathrm{O}^{2}$ ); loss of water is not observed from the CID of $m / z 70$. Intermediate $a$ in Scheme II also gives rise to $m / z 40$, which is sitespecific at $\mathrm{N}-1, \mathrm{C}-6$, and $\mathrm{C}-5$, presumably through stepwise eliminations of molecules of $\mathrm{H}_{2} \mathrm{O}, \mathrm{CO}$, and then HCN (not shown in Scheme I). The ion at $m / z 40$ is not observed following principal dissociation steps for loss of $\mathrm{NH}_{3}$ and $\mathrm{HNCO}$. A neutral loss of ammonia is observed following collisional activation of $\mathrm{m} / \mathrm{z} 70$ and yields a product at $m / z 53$, which is entirely site-specific for $\mathrm{C}-4, \mathrm{O}^{4}, \mathrm{C}-5$, and $\mathrm{C}-6$ (Table 2).

The EI mass spectrum of uracil contains two different fragment ions with the same nominal mass at $\mathrm{m} / \mathrm{z}$ $41\left(\mathrm{C}_{2} \mathrm{HO}^{+}\left[\mathrm{O}^{4}, \mathrm{C}-4, \mathrm{C}-5\right]\right.$ and $\mathrm{C}_{2} \mathrm{H}_{3} \mathrm{~N}^{+}[\mathrm{N}-1, \mathrm{C}-5$, $\mathrm{C}-6])[16,17]$, which require high resolution mass spectrometry to identify. Collisional activation of protonated uracil generates product ions that contain the same specific skeletal atoms as those found by EI, but are easily distinguishable at $m / z 43$ and 42 (resuliting from losses of $\mathrm{HCN}$ and $\mathrm{CO}$ from $\mathrm{m} / \mathrm{z} 70$, shown in Scheme I), due to different hydrogen content.

The interesting low mass ion at $m / z 15\left(\mathrm{CH}_{3}^{+}\right)$ originates about equally from $\mathrm{C}-5$ and $\mathrm{C}-6$, as shown in Table 2 , based on relative intensities observed in the CID spectrum of $\left[4,5-{ }^{13} \mathrm{C}_{2}\right]$ uracil. The $\mathrm{CH}_{3}^{+}$ion comprised of C -6 must be a direct dissociation product from $m / z 70$, because of compositional constraints on further dissociations of $m / z 53,43$, and 42 (Scheme T). However, $\mathrm{CH}_{3}^{+}$originating from the $\mathrm{C}-5$ position may be derived from $m / z 70,43$, or 42 , based on the site-specific compositions of these ions.

\section{Influence of Substitution in the Pyrimidine Ring}

The CID mass spectra of 2-thiouracil, 4-thiouracil, and 2-thiothymine (Figure 5), as well as 3-methyluracil and a series of C-5-substituted uracil models (Figure 6). were studied to determine the specific effects these structural modifications have on the dissociation reactions established for protonated uracil described in the preceding sections. All of the models selected represent common and important forms of natural modification in RNA [35]. The principal reaction paths generally follow the behavior of uracil, with appropriate mass shifts observed for substitution. A number of additional product ions are also observed as a result of the nature of the substituent which reflect changes in the site and extent of protonation, as well as sulfur and alkyl stabilization efferts which influence fragmentation in the classic manner [36]. Substitutions involving thiation and methylation effect increased dissociation reactions and charge retention at the site of these substitutions, resulting in significant increases in the intensity of some minor product ions. In particular, secondary elimination reactions resulting in loss of a
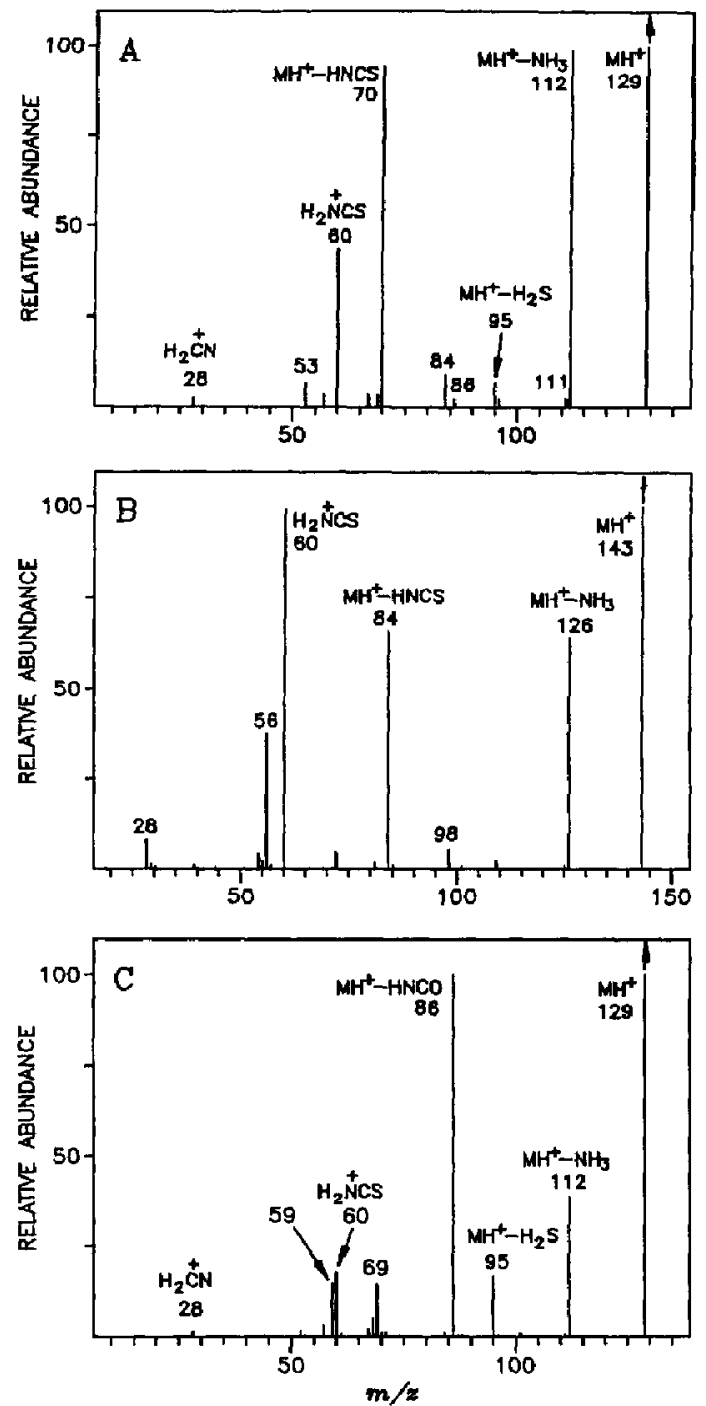

Figure 5. CID mass spectra of protonated: (a) 2-thiouracil; (b) 4-thiouracil; (c) 2-thio-5-methyluracil.

neutral molecule of $\mathrm{CO}$ (or $\mathrm{CS}$ ) following initial dissociations of $\mathrm{NH}_{3}$ and $\mathrm{HNCO}$ show substantial increases with any substitution at the $\mathrm{C}-5$ position, as discussed below.

For the thio-substituted uracils, changes in the relative abundances of $\left[\mathrm{MH}^{+}-\mathrm{HNCO}(\mathrm{S})\right]$ and the corresponding $\mathrm{H}_{2} \mathrm{NCO}(\mathrm{S})^{+}$ion, resulting from the RDA reaction (Scheme II, eq. 4), reflect either greater extent of protonation at sulfur or increased charge stabilization associated with the RDA pathway. For instance. 2-thiouracil and 2-thiothymine (Figure 5a and b) show major increases in the relative intensity of $\mathrm{H}_{2} \mathrm{NCS}^{+}$ ( $m / z$ 60) compared with $\mathrm{H}_{2} \mathrm{NCO}^{+}(m / z$ 44) of uracil (Figure 2), and a corresponding decrease in $\left[\mathrm{MH}^{+}-\right.$ 

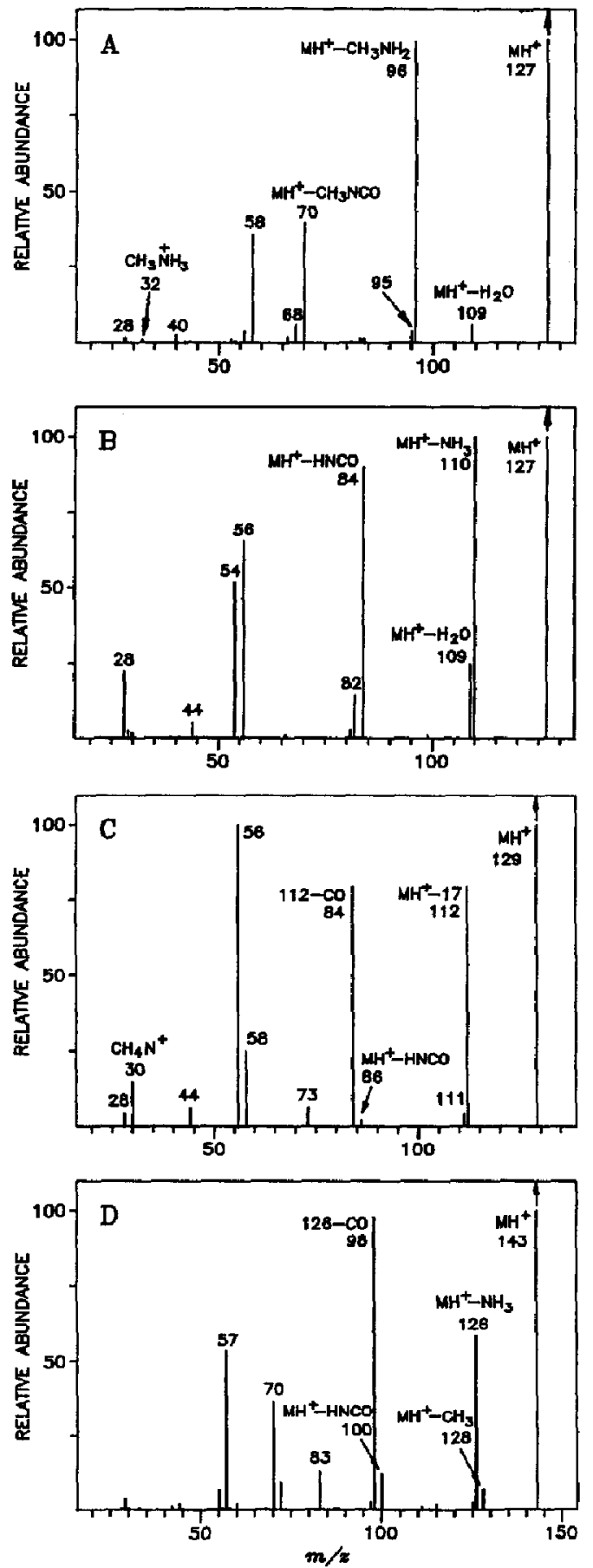

Figure 6. CID mass spectra of protonated: (a) 3-methyluracil; (b) 5-methyluracil; (c) 5-hydroxyuracil; (d) 5-methoxyuracil.
HNCS] is seen. Similarly, in Figure 5c, increased protonation or charge stabilization at S-4 of 4 -thiouracil is indicated by the relative abundance of the product ion at $m / z 59$, which can be interpreted in terms of stepwise eliminations of $\mathrm{HNCO}$ from the RDA reaction followed by loss of a molecule of HCN as described in Scheme I for uracil. The interpretation that these changes are a consequence of greater extent of protonation at sulfur (versus oxygen in uracil) are supported both by gas-phase proton affinity (PA) data, and $\mathrm{pK}_{\mathrm{a}}$ values. 2,4-Dithiouracil is reported to have a PA of up to $15 \mathrm{kcal} / \mathrm{mol}$ greater than that of uracil [37], reflecting a general basicity trend for replacement of $O$ by $S[38,39]$. Similarly, increased basicity in solution is shown by the $\mathrm{pK}_{\mathrm{a}}$ 's of 2-thioruridine, 8.8 , and 4-thiouridine, 8.2, compared with uridine, 9.3 [40].

The characteristic expulsion of HNCO or HNCS can be utilized to identify the position of thiation in substituted pyrimidines. Differentiation of 2- and 4thiouracil based on the RDA elimination reaction has been previously reported for EI mass spectra [41, 42]. Thio substitution also influences the relative elimination of $\mathrm{H}_{2} \mathrm{~S}$ versus $\mathrm{H}_{2} \mathrm{O}$ from the protonated molecule (Figure $5 \mathrm{a}$ and $\mathrm{b}$ ). $\mathrm{H}_{2} \mathrm{~S}$ is preferentially expelled $(\mathrm{m} / \mathrm{z}$ 95) from both 2- and 4-thiouracil (in comparison with uracil which loses $\mathrm{H}_{2} \mathrm{O}$ equally from $\mathrm{O}^{2}$ and $\mathrm{O}^{4}$, Table 1), which, in part, may be attributed to the influence of site-of-protonation in generating different reaction channels.

Secondary dissociation reactions of thiouracils closely parallel those of uracil (shown in Scheme I) but minor product ions involving the site of substitution typically are much more abundant. 4-Thiouracil, for example, loses a molecule of CS after elimination of ammonia (producing $m / z$ 68); 2-thiouracil loses $C O$ primarily from $\mathrm{C}-4$ following loss of $\mathrm{NH}_{3}$, analogous to uracil (Table 1). The minor product ion at $m / z 42$ of uracil (Figure 2, Scheme I) shifts to $m / z 56$ in the CID spectrum of 2-thiothymine (Figure $4 \mathrm{~b}$ ) as a result of the additional methyl at C-5. The significant increase in this reaction path probably occurs as a result of greater charge stabilization at C-5 from the methyl substituent at $\mathrm{C}-5$, following expulsion of $\mathrm{CO}$ from $m / z 84$.

Substitution at N-3 of pyrimidines is readily identified by two of the three principal dissociations analogous to uracil which involve loss of N-3 $\left(\mathrm{IMH}^{+}\right.$ $\mathrm{NH}_{3}$ ], $\left[\mathrm{MH}^{+}-\mathrm{HNCO}\right]$ and their complementary protonated species. Collisional activation of 3-methyluracil (Figure 6a), for instance, generates product ions at $m / z 96,70,58$, and 32 , corresponding to $\left[\mathrm{MH}^{+}-\right.$ $\left.\mathrm{NH}_{2} \mathrm{CH}_{3}\right],\left[\mathrm{MH}^{+}-\mathrm{CH}_{3} \mathrm{NCO},\left[\mathrm{CH}_{3} \mathrm{HNCO}\right]^{+}\right.$, and $\left[\mathrm{CH}_{3} \mathrm{NH}_{3}\right]^{+}$, respectively. The appearance of the relatively intense peak at $m / z 58$ (shifted in mass from the minor $m / z 44$ ion of uracil; see Table 2) occurs from the $R D A$ reaction and is interpreted in terms of increased charge retention at the site of substitution as a result of changes in the site of protonation or increased stabilization from the methyl substituent. 
Substitution by methylation, hydroxylation, or methoxylation at C-5 of uracil results in several notable differences in dissociation channels compared with uracil. These differences include the following: (1) the RDA reaction is a major pathway for 5-methyluracil, but is greatly diminished for 5-hydroxyuracil and 5-methoxyuracil; (2) elimination of $\mathrm{NH}_{3}$ is still a major dissociation pathway from $\mathrm{MH}^{+}$, but subsequent successive losses of $\mathrm{CO}$ dramatically increase (Figure 6b, c, d); (3) hydroxylation or methoxylation results in decreased pathways for lass of $\mathrm{H}_{2} \mathrm{O}$ from $\mathrm{MH}^{+}$(Figure 6c, d); and (4) hydroxylation or methoxylation also inhibits secondary dissociation paths leading to formation of minor product ions corresponding to $m / z 52$ and 43 of uracil. Some of the ions selectively derived from the $\mathrm{O}^{4}, \mathrm{C}-4, \mathrm{C}-5$, and $\mathrm{C}-6$ portion of the pyrimidine ring are not observed. The above changes are unlikely to be due to protonation of the $\mathrm{O}^{5}$ substituent, but reflect changes in electron density in the pyrimidine ring resulting from oxygen substitution.

Ions generated by loss of $\mathrm{CO}$ following the RDA elimination from 5 -methyluracil $(m / z 56$, Figure $5 b)$ and 5-hydroxyuracil ( $m / z 58$, Figure $5 c$ ) and consecutive losses of two molecules of $\mathrm{CO}(\mathrm{m} / z 54$, Figure $5 b$, and $m / z 56$, Figure 5c) following elimination of $\mathrm{NH}_{3}$ from $\mathrm{MH}^{+}$, are particularly increased in relative intensity compared with uracil (analogous pathways for $m / z 42$ and 40). An aziridine ring structure was previously proposed for the $m / z 54$ ion based on EI studies of 5-methyluracil [16]. Methyl substitution at C-5 may generate increased decarbonylation through a vinyl carbonium ion intermediate similar to mechanisms proposed by Rice et al. [16] in which $\mathrm{CO}$ is expelled from $\mathrm{C}-4, \mathrm{O}^{4}$, in agreement with earlier discussion for loss of CO from uracil (Table 1). By comparison with EI spectra of uracil and 5-methyluracil, such dramatic site-directed effects are not observed upon methyl substitution.

\section{Conclusions}

Natural and synthetic modifications of the major nucleic acid bases uracil and 5-methyluracil (thymine) are of broad interest in chemistry and biology [43-45]. The role of mass spectrometry in structural studies of these and other nucleic acid constituents at the monomer level has been significant [46, 47], and should continue to expand with the advent of new methods that are particularly applicable in nucleic acid chemistry [48-50]. The present study demonstrates that collision-induced reactions of protonated uracil build on existing knowledge of the dissociation chemistry of corresponding odd-electron ions [17], and offers a potentially effective means for structural characterization using tandem mass spectrometry. Taken together with earlier studies of adenine [10] it is evident that CID of the protonated nucleic acid bases follows better defined and interpretable reaction paths than were predicted a priori from much of the earlier literature [1].

\section{Acknowledgments}

This work was supported by grant nn. GM 21584 from the National Institutes of Health. We are grateful to $K$. H. Schram and $T$. Hashizume for the preparation of several model compounds in conjunction with earlier studies, to M. P. Schweizer and C. D. Poulter for gifts of reference materials, and to J. L. Stauffer and S. C. Pomerantz for technical assistance.

\section{References}

1. Mass Spectrometry of Heterocyclic Compounds; Porter, Q. M., Ed. Wiley: New York, 1985.

2. Busch, K. L.; Glish, G. L.; McLuckey, S. A. Mass Spectromtetry/Mass Spectrometry: Techniques and Applications of Tandem Mass Specironelry; VCI I Publishers: New York, 1988.

3. For discussion and references to leading examples, see: Hayes, R. N.; Gross, M. L. Methods Enzymol. 1990, 193, 237-263.

4. Gross, M. L. Methods Enzymol. 1990, 193, 131-153.

5. Yost, R. A.; Boyd, R. K. Methads Enzymol. 1990, 193, 154-200.

6. Schram, K. H. In Mass Spectrometry; Lawson, A. M., Ed. Walter de Gruyter: New York, 1989; pp. 507-570.

7. Crain, P. F. Mass Spectrom. Rev. 1990, 9, 505-554.

8. McCloskey, J. A. In Basic Principles in Nucleic Acid Chemistry; Ts'o, P. O. P., Ed. Academic Press, New York, 1974; Vol. I, Pp. 209-309.

9. Alexander, A. J.; Kebarle, P.; Fuciarelli, A. F.; Raleigh, J. A. Anal. Chem. 1987, 59, 2484-2491.

10. Nelson, C. C.; McCloskey, J. A. I. Am. Chem. Soc, 1992, 114, 3661-3668.

11. Sakurai, T.; Matsuo, T.; Kusai. A.; Nojima, K. Ropid Commun. Mass Spectrom. 1989, 3, 212216.

12. Ikonomou, M. G.; Naghipur, A.; Lown, J. W.; Kebarle, P. Biomed. Environ. Mass Spectrom. 1990, 19, 434-446.

13. Shannon, J. S.; Letham, D. S. N.Z. J. Sci. 1966, 9, 833-842.

14. Rice, J. M.; Dudek, G. O. I. Am. Chem. Soc. 1967, 89, $2719-2725$.

15. McCloskey, J. A.; Crain, P. F. Int. J. Mass Spectrom. Ion Processes 1992, 118/119, 593-615.

16. Rice, J. M.; Dudek, G. O.; Barber, M. J. Am. Chem. Soc. 1965, $87,4569-4576$.

17. For compilation of FI mass spectra of uracil derivatives, see: Hignite, C. In Biochemical Applications of Mass Spectronetry; Waller, G. R., Ed. Wiley-Interscience: New York, 1972; pp. 429-447.

18. Griffey, R. H.; l'oulter, C. D. Nucleic Acids Res. 1983, 11, $6497-6504$.

19. Solsten, R. T.; McCloskey, J. A.; Schram, K. H. Nucleosides and Nucleotides 1982, 1, 57-61.

20. Kinoshita, T.; Schram, K. H.; McCloskey, J. A. J. Labelled Compds, and Radiopharm. 1981, IX(4), 525-534.

21. Puzo, G.; Schram, K. H.; McCloskey, J. A. Nucleic Acids Res 1977, 4, 2075-2082.

22. Puzo, G.; Wiebers, J. L. Nucleic Acids Res. 1981, 9, 4655-4667.

23. Sethi, S. K.; Gupta, S. P.; Jenkins, E. E.; Whitehead, C. W.; Townsend, L. B.; McCloskey, J. A. I. Am. Chem. Soc, 1982, 104, 3349-3353.

24. dePauw, E. Mass Spectrom. Rev. 1986, 5, 191-212.

25. Ts'o, P. O. P. In Basic Principles in Nucleic Acid Chemistry; Ts'o, P. O. P., Ed. Academic Press: New York, 1974; Vol. I, p. 453.

26. Snegner, W. Principles of Nucleic Acid Structure; SpringerVerlag: Berlin, 1984; pp. 105-115.

27. Hass, E. C.; Mezey, P. G.; Ladik, J. J. Theoret. Chim. Acta (Berlin) 1981, 60, 283-297.

28. Del Bene, J. E. J. Phys. Chem. 1983, 87, 367-371. 
29. Kenttämaa, H. I. Org. Mass Spectrom. 1985, 20, 703-714, and references therein.

30. Crow, F. W.; Tomer, K. B.; Gross, M. L.; McCloskey, J. A.; Bergstrom, D. E. Anal. Biochem. 1984, 139, 243-262.

31. Claereboudt, J.; Esmans, E. L.; Claeys, M. Biol. Mass Spectrom. 1993, 22, 419-421.

32. Weisz, A.; Therkleid, E.; Mandelbaum, A.; Blum, W.; Richter, W. J. Org. Mass Spectrom. 1987, 22, 3-5.

33. Vincenti, M.; Homing, S. R.; Cooks, R, G. Org. Mass Spectrom. 1988, 23, 585-593.

34. Derrick, P. J.; Falick, A. M.; Burlingame, A. L. J. Am. Chem. Soc. 1972, 94, 6794-6802.

35. Dirheimer, G. Recent Results Cancer Res. 1983, 84, 1-46.

36. Biemann, K Mass Spectrometry: Organic Chertical Applicationts; MoGraw-Hill: New York, 1962; pp. 46-161.

37. Wilson, M. S.; MeCloskey, J. A. J. Am. Chem. Soc. 1975, 97, 3436-3444.

38. Haney, M. A.; Franklin, J. L. J. Phys. Chem. 1969, 73, 4328-4331.

39. Beauchamp, J. L. Annu. Rev. Phys. Chem. 1971, 22, 527-561.

40. Saenger, W. Principles of Nucleic Acid Structure; SpringerVerlag, Berlin, 1984; pp. 110-111.
41. Rieser, R. W. Org. Mass Spectrom. 1969, 2, 467-479.

42. Hecht, S. M.; Gupta, A. S.; Leonard, N. J. Biachem. Biophys, Acta 1969, 182, $444 \cdot 448$.

43. Scheit, K. H. Nucleotide Analogs, Synthesis and Biological Function: Wiley: New York, 1980.

44. Mizuno, Y. The Organic Chemistry of Nucleic Acids; Elsevier: Amsterdam, 1986.

45. Björk, G. R.; Ericson, J. U.; Gustafsson, C. E. D.; Hagervall, T. G.; Jönsson, Y. H.; Wikström, P. M. Annu. Rev. Biochem. $1987,56,263-287$.

46. McCloskey, J. A. Acc. Chem. Res. 1991 24, 81-88.

47. Crain, P. F.; Hashizume, T.; Nelson, C. C.; Pomerantz, S. C.; McCloskey, J. A. In Biological Mass Spectrometry; Burlingame, A. L; McCloskey, J. A., Eds. Elsevier; Amsterdam, 1990; pp. 509-526.

48. Smith, R. D.; Loo, J. A.; Edmonds, C. G.; Barinaga, C. J.; Udseth, H. R. Anal. Chem. 1990, 62, 882-899.

49. Methods and Mechanisms for Producing Ions from Large Molecules; Standing, K. G.; Ens, W., Eds. Plenum: New York, 1991.

50. Kowalak, J. A.; Pomerantz, S. C.; Crain, P. F.; McCloskey, J. A. Nucleic Acids Res. 1993, 21, 4577-4585. 